Research Article

\title{
Experimental and Numerical Simulation Study on the Shear Strength Characteristics of Magnolia multiflora Root-Soil Composites
}

\author{
ZiFan Sui, ${ }^{1}$ Wen Yi ${ }^{1},{ }^{1}$ YunGang Lu, ${ }^{2}$ and Liang Deng ${ }^{2}$ \\ ${ }^{1}$ Central South University of Forestry \& Technology, Changsha 410004, Hunan, China \\ ${ }^{2}$ Hunan Expressway Group Co., Ltd., Changsha 410026, Hunan, China
}

Correspondence should be addressed to Wen Yi; yiwengangbiao@163.com

Received 21 December 2020; Revised 17 April 2021; Accepted 6 May 2021; Published 19 May 2021

Academic Editor: Hui Yao

Copyright (c) $2021 \mathrm{ZiFan}$ Sui et al. This is an open access article distributed under the Creative Commons Attribution License, which permits unrestricted use, distribution, and reproduction in any medium, provided the original work is properly cited.

The shear strength of the soil refers to the ultimate strength of the soil against shear failure, which is one of the important indicators used to measure slope stability. This paper presents a simulation of direct shear tests on root-soil composites with different root embedding angles under different stress conditions. By comparing and analyzing the simulation results of ABAQUS software and the laboratory test results, the enhancement effect of plant roots on soil shear strength was explored. Conclusions can be drawn as follows: the excellent agreement between numerical models and laboratory shear tests suggested that the developed model can quickly and conveniently predict the shear strength of the root-soil composites. The shear strength was related to the rooting arrangement. For a single root system, when the inclination angle of the root was about $64^{\circ}$ to the shear direction, the shear resistance of soil was much improved, while the root reinforcement had less effect when the inclination angle was greater than $90^{\circ}$. In the case of multiple roots, the hybrid rooting method can more effectively improve the shear resistance of the root-soil composite. Therefore, in the practical application of using the root to strengthen the soil, the angle of a single root and arrangement of multiple roots should be comprehensively considered.

\section{Introduction}

Before the end of 2019, the total mileage of highways in China has exceeded 5.0125 million kilometers. However, Slopes are inevitably generated during mountain road constructions; these kinds of the slope are prone to landslides and other geological problems, such as soil erosion. All these problems seriously affect road traffic safety and the ecological environment $[1,2]$. To solve these problems, soil bioengineering techniques have emerged, which can not only stabilize the slope but also prevent soil erosion, save engineering costs, and beautify the road landscape [3-6].

The interaction between soil and plant roots mainly contributes to plant slope protection [7]. According to the theory of composite materials, plant roots can be treated as flexible reinforcement materials, which improve the shear strength of soil $[8,9]$. Since 1970, many works studied the stress-strain and strength characteristics of the reinforced soil and the effect of the roots on the soil through experiments such as direct shear tests and triaxial tests [10-14]. In the 1980s, Wu et al. [15] proposed a cementing relationship between the roots and soil and make the research on the mechanical mechanism of root fixation to a higher level. $\mathrm{Wu}$ et al. $[16,17]$ elaborated the concept of the "soil-root composites" and analyzed the relationship between the shear strength and normal pressure, root content, water content, and other factors through laboratory tests. The results suggested that the mechanical reinforcement of the root system was related to the strength of soil and roots and the environmental conditions, especially the changes in stress and moisture $[18,19]$. At the same time, in order to effectively improve the reinforcement effect of the roots on the soil, Ted et al. [20-22] have carried out research on plant root growth regulation. By changing factors such as moisture and phosphate content in the soil, people can control the growth direction of plant roots to achieve the desired effect. 
Most scholars have researched the shear performance of root-soil composites through experimental methods. The mechanism of shear behavior depends on the interaction of friction and constraint between root and soil. The shear characteristics of the root-soil composite are affected by many factors, such as the internal friction angle, cohesion force, and water content of the soil [23]. The improvement of shear strength of the soil is the main feature of the root reinforcement, which is influenced by moisture content, diameter, and root morphology of a single root [24]. Besides, considering the fact that plants require time to grow, the root used in the soil sample in the direct shear test is not entirely the same as the root in the original soil. These modeling conditions are difficult to be reconstructed in shear tests in the laboratory. Furthermore, the growth rate of root biomass was uneven, and the proportion of adventitious roots was prominent during the juvenile period [25]. Therefore, it is more complicated and inaccurate to study the individual action of root using experimental methods.

Various finite element numerical analysis software products have been used to analyze actual engineering problems [26]. Considering the difficulties in testing rootsoil composites, an increasing number of research cases adopted numerical simulation software to analyze the mechanical interaction between roots and soil [27, 28]. Moreover, the finite element numerical simulation can accurately simulate the characteristics of the root-soil composite material due to its broad applicability and easy parameter definition. In 2010, Lin et al. [29] established a 3D model of Makino bamboo T-shaped taproot and fibrous root, which was used in the numerical simulation study of the pullout test and analyzed the effect of the bamboo root system on the slope stability. In 2011, Mickovski et al. [30] compared and analyzed the difference between 2D and 3D simulations of plant roots. Considering the complexity of the spatial distribution of roots, it is generally believed that the accuracy of the 3D model is higher. There are four main types of calculation models commonly used in root-soil interaction [31]: the first type assumes that the root system of the plant and the soil are separated from each other, ignoring the movement between the two [32]. The second category regards the effects of plant roots as external loads imposed on the soil [33]. The third category comprehensively considers the frictional contact relationship between the soil and the root system [34]. The fourth category regards the combination of root and soil as a composite material [24]. Depending on the research focus, it is particularly important to choose a suitable calculation mode.

In order to quickly and conveniently analyze the effect of root on soil reinforcement, we explore the best arrangement of the root system in soil and enrich the theory of root-soil consolidation and numerical simulation-related research. In this study, through ABAQUS finite element software, the direct shear friction test of the Magnolia multiflorum root and soil interface was simulated numerically, and the results were compared with laboratory test results to analyze the feasibility of the numerical simulation model, which laid a foundation for the exploration of the best root percentage and the best root distribution method. The paper is organized as follows: the root-soil composite material was sampled on-site, and the cohesion force, friction angle, root diameter, length, and other related parameters were measured through the indoor test. On this basis, a finite element model of the root-soil composite material was constructed. Subsequently, the effectiveness of the finite element model was verified by comparing test data with simulation results. Simultaneously, the best embedding angle of a single root system and the best rooting method of multiple root systems were discussed with the help of the model.

\section{Materials and Methods}

2.1. The Mechanism of Root Strengthening Soil. The root embedded in the soil will be stretched and produce tension when the soil is sheared. The tension force can be decomposed into the horizontal direction and vertical direction, the horizontal force can be directly used to resist shear deformation, and the vertical force can be converted to positive stress to increase the friction force. When the root was inserted vertically into the soil, the incremental shear strength of the root-soil composite can be calculated by the following equation.

When the root system is orthogonal to the shear plane (Figure 1(a)),

$$
\begin{aligned}
\Delta S & =\left(\frac{T}{A_{S}} \sin \theta+\frac{T}{A_{S}} \cos \theta \cdot \tan \varphi\right), \\
\sin \theta & =\frac{x}{\sqrt[2]{x^{2}+H^{2}}}, \\
\cos \theta & =\frac{H}{\sqrt[2]{x^{2}+H^{2}}} .
\end{aligned}
$$

When the root system is oblique to the shear plane (Figure 1(b)),

$$
\begin{aligned}
\Delta s & =\frac{T}{A_{s}} \sin \left(90^{\circ}-\psi\right)+\frac{T}{A_{s}} \cos \left(90^{\circ}-\psi\right) \cdot \tan \phi, \\
\psi & =\arctan \left(\frac{x}{(x+H) / \tan a}\right),
\end{aligned}
$$

where $\Delta S$ is the cohesion increment, $T$ is the tension force generated by root, $A_{S}$ is the cross-sectional area, $\theta$ is the angle between the root with the vertical direction after deformation, $\varphi$ is the internal friction angle, $x$ is the maximum shear displacement, $H$ is the length of the sheared part of the root, $\psi$ is the angle between the root and the shear surface after shear deformation, and a is the angle formed between the root of the initial state and the shear surface $\left(0^{\circ} \ll a \ll 180^{\circ}\right)$.

The shear strength of the soil and its increment of cohesion force can be calculated for different root angles. The results were further explored to determine the most appropriate root embedding angle, which would improve the shear resistance of soil and enhance the stability of the slope most. Based on the results of the field tests, Likitlersuang 


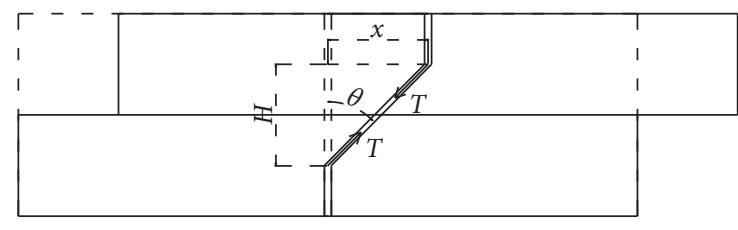

(a)

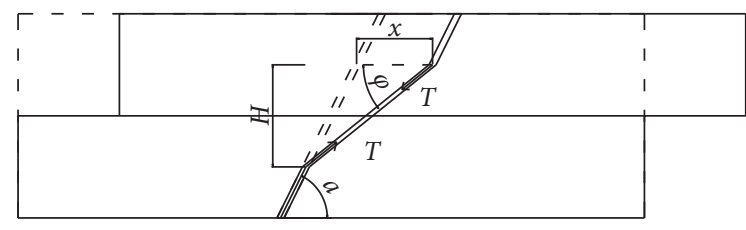

(b)

FIgURE 1: Root deformation diagram: (a) the root is orthogonal to the shear plane; (b) the root intersects the shear plane obliquely.

et al. [35] calculated the displacement of the root-soil composite at maximum shear strength as shown in

$$
x=\frac{0.72 A_{r}}{A_{s}+13.3},
$$

where $A_{r}$ is the total area of the root system on the shear plane.

There have been few studies on the thickness of the shear zone $H$. A fixed value of $H=5 \mathrm{~mm}$ is usually taken in the calculation, which will produce errors with the actual test situation. The actual deformation of the root in the soil can be observed, and the thickness of the shear zone can be calculated by

$$
H=\frac{X}{\tan \left(90^{\circ}-\psi\right)} .
$$

After understanding the reinforcement mechanism of the root system to the soil, further relevant experiments and numerical simulation studies were carried out, and the feasibility of the model was verified by comparing the errors between the simulated values and the experimental and theoretical values.

2.2. Introduction of the Study Area. The study area is located in the Yueyang section of the Da-Yue highway (east longitude $112^{\circ} 10^{\prime} 3^{\prime \prime}$ to $114^{\circ} 9^{\prime} 6^{\prime \prime}$, north latitude $28^{\circ} 25^{\prime} 33^{\prime \prime}$ to $\left.29^{\circ} 48^{\prime} 47^{\prime \prime}\right)$, which has a humid continental monsoon climate. Its annual average temperature is between $16.5^{\circ} \mathrm{C}$ and $17.2^{\circ} \mathrm{C}$, the highest temperature ranges from $39.3^{\circ} \mathrm{C}$ to $40.8^{\circ} \mathrm{C}$, the lowest extreme temperature ranges from $-11.4^{\circ} \mathrm{C}$ to $-18.1^{\circ} \mathrm{C}$, and the average annual precipitation is from 1289.8 to $1556.2 \mathrm{~mm}$. There is more rainfall in the eastern part than the western part of the test section. The same area has more rainfall in spring and summer than autumn and winter. The studied slope is relatively high, with the highest point at 36.31 meters. Considering the effect and aesthetics of slope protection, we selected Magnolia multiflorum, Robinia pseudoacacia, Cynodon dactylon, and Cobus chrysanthemum as the slope protection plants. The landscape of the slope before and after protection is shown in Figure 2.

We used a ring knife to select soil on the test slope as the test soil. By referring to "Test Methods of Soils for Highway Engineering" in China, the soil water content was measured as $15.3 \%-21.4 \%$ by oven drying method. The natural density of the soil was tested as $1.65 \mathrm{~g} / \mathrm{cm}^{3}-1.82 \mathrm{~g} / \mathrm{cm}^{3}$ through the cutting ring method, and the particle composition of the soil was obtained through the sieving analysis test and is listed in Table 1 . The plasticity index of the soil measured by the photoelectric liquid-plastic-limit combined analyzer is $22.9 \%$, which is greater than $17 \%$, so the soil is determined to be clay.

2.3. Collection of the Root Sample. The horizontal excavation method was used to collect the plant roots for experimental research. After excavating, the roots were wrapped in the soil sample and placed in a shear box and were watered for proper conservation. In this test, the diameter of Magnolia multiflorum was measured as $0.6-0.8 \mathrm{~mm}$ by using the vernier caliper, as shown in Figure 3. In order to prevent the root system from losing nutrients, it should be noted that the test should be completed within one month after roots were collected.

2.4. Direct Shear Test of Root-Soil Composites. The direct shear test was used in this paper because of its simple and easy operation. ZJ strain-controlled quadruple direct shear instrument produced by the Nanjing Soil Instrument Factory was chosen.

An iron wire was inserted to ensure the buried root position while preparing cylindrical specimens with a diameter of $61.8 \mathrm{~mm}$ and a height of $20 \mathrm{~mm}$. The moisture content of the soil sample is consistent with that of the slope site soil, and its value is $18.62 \%$, the iron wire was removed to insert the root, and the hole was compacted with soil. Then, the sample was covered with filter paper and pervious stone before being pushed into the shear box. During the test, vertical pressures of $100 \mathrm{kPa}, 150 \mathrm{kPa}, 200 \mathrm{kPa}$, and $250 \mathrm{kPa}$ were applied to each group of specimens. The transmission was opened to shear at a speed of less than $0.02 \mathrm{~mm} / \mathrm{min}$ until the shear damage occurred; during the process, the device automatically records the shear stress. In the shearing process, as the shear deformation of the root-soil composite increased, the shear strength of the root-soil composite was equal to shear stress when the shear failure occurred. The test process is shown in Figure 4.

Magnolia multiflorum roots were used as the test subjects, and three kinds of root angle of $90^{\circ}, 90^{\circ}+45^{\circ}$, and $45^{\circ}$ root were used. To obtain the shear strength of soil, it is necessary to draw its stress-strain curve in the direct shear test. During the test, for specimens without root or the rootsoil composite, as dislocation appeared between the upper and lower shear boxes, the shear stress increased approximately linearly with the change in displacement and finally reached a stable value which was the shear strength. The relationship between shear strength and shear displacement was fitted as follows [36]: 


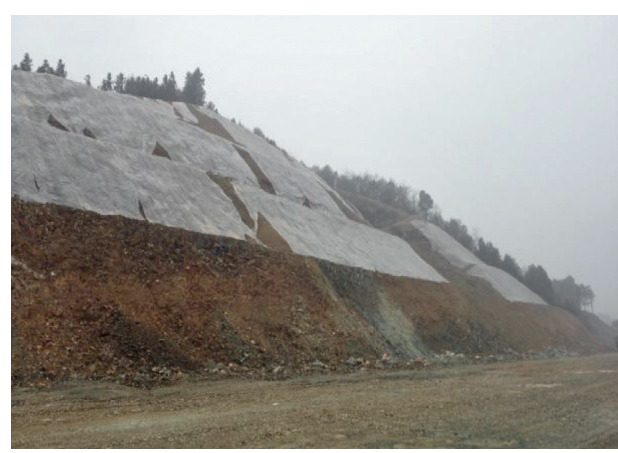

(a)

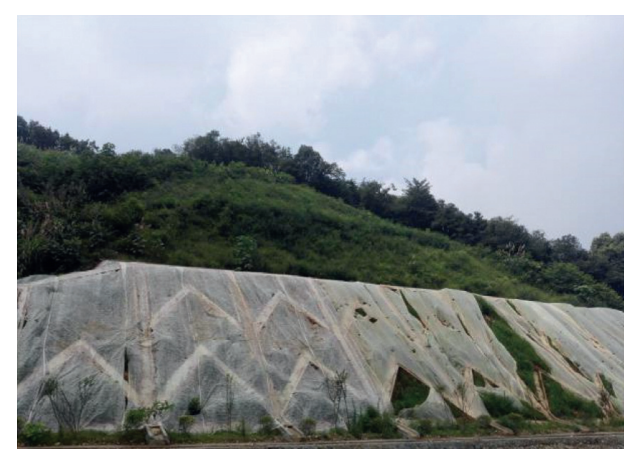

(b)

FIGURE 2: Landscape of studied slope: (a) before slope protection; (b) after planting plants.

TABLE 1: Results of sieving analysis test.

\begin{tabular}{lccc}
\hline Screen hole diameter $(\mathrm{mm})$ & Percentage $(\%)$ & Screen hole diameter $\left(^{\circ}\right)$ & Percentage $(\%)$ \\
\hline 40 & 0 & 1 & 11.8 \\
20 & 5.0 & 0.5 & 15.3 \\
10 & 14.2 & 0.25 & 5.7 \\
5 & 17.8 & 0.075 & 1.5 \\
2 & 28.3 & $<0.075$ & 0.3 \\
\hline
\end{tabular}

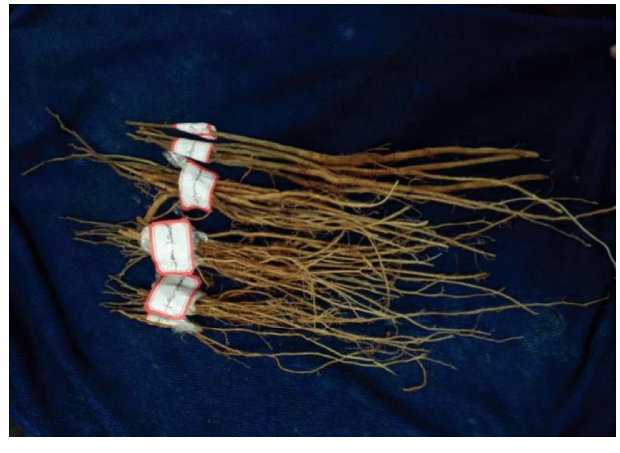

(a)

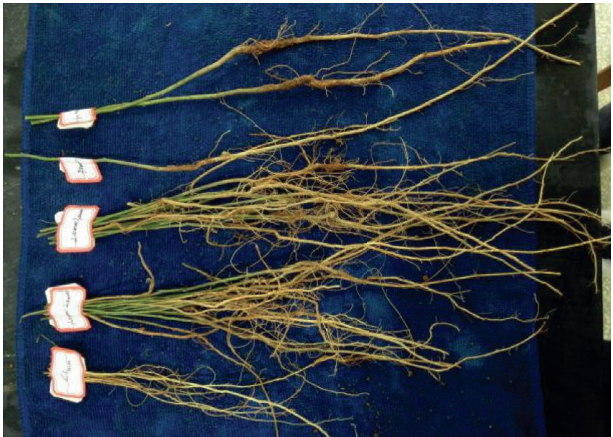

(b)

FIGURE 3: Morphological characteristics of different root systems: (a) root system with a length of about $20 \mathrm{~mm}$; (b) root system with a length of about $28.8 \mathrm{~mm}$.

$$
\frac{\Delta l}{\tau}=a \Delta l+b
$$

where $\Delta l$ is the shear displacement and $a$ and $b$ are the constants.

Multiple groups of laboratory direct shear tests were performed to record the corresponding shear strength under each vertical pressure. The direct shear test results were analyzed, and the relationship curve between the shear strength and normal stress of the root-soil composites was fitted in Table 2. According to the analysis, the shear strength increased with the increase of vertical load under the same root number and root pattern. The results showed that as the vertical load increased, the shear strength increased, which was a linear relationship for cohesive soils that can be expressed by equation (2). Comparing equation (2) with the fitting formula in Table 3, the cohesive force and internal friction angle of the material can be calculated. The cohesion force and the internal friction angle of the ordinary soil and root-soil composites can be used for slope stability analysis.

$$
\tau=c+\sigma \tan \varphi
$$

where $\tau$ is the shear strength, $c$ is the cohesion, and $\varphi$ is the internal friction angle.

2.5. Numerical Modeling of the Direct Shear Test. The solid model with a diameter of $61.8 \mathrm{~mm}$ and a height of $20 \mathrm{~mm}$ was established to maintain the same size as the actual soil sample. It meshed with a three-dimensional first-order hexahedron element (C3D8), including a total of 564 nodes and 870 nodes. In the finite element simulation, the MohrCoulomb ideal plasticity model was applied. The specific values are shown in Table 2.

Plant roots can be divided into three types according to their morphology: straight type, scattered type, and 


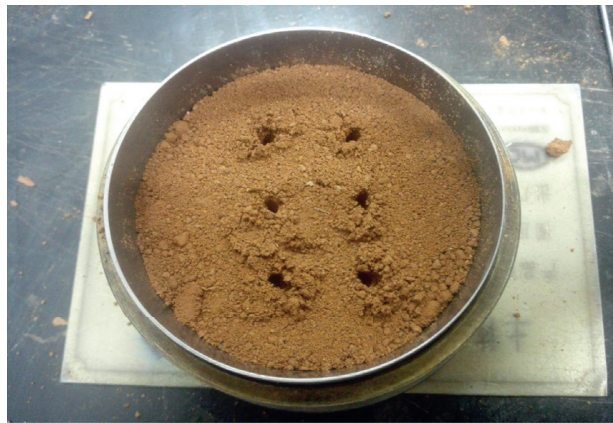

(a)

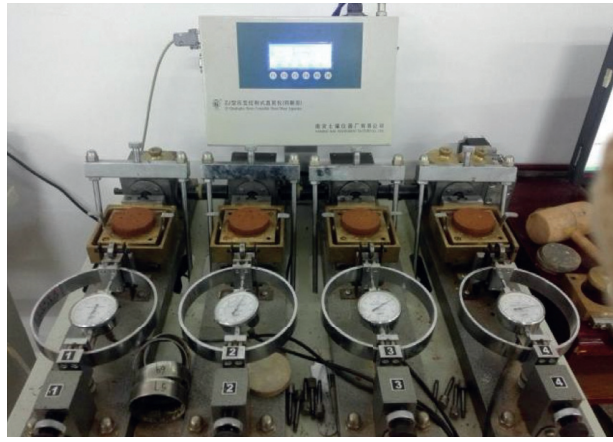

(c)

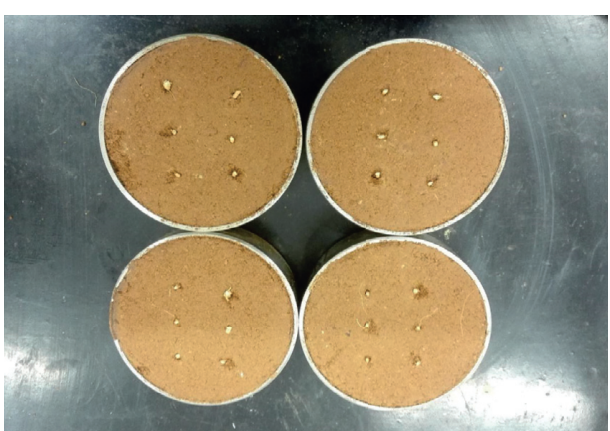

(b)

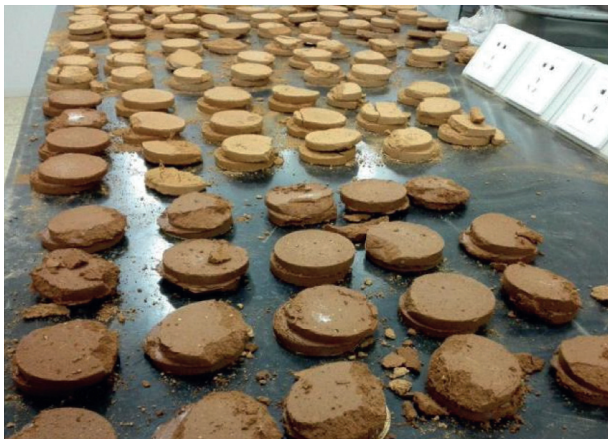

(d)

FIgURE 4: Shear test process of root-soil composites: (a) perforated cloth root of the direct shear specimen; (b) finished sample. (c) direct shear devices; (d) specimens after shear failure.

TABLE 2: Soil parameters in the numerical simulation.

\begin{tabular}{lcc}
\hline Parameter & Value & Unit \\
\hline Soil density & 1450 & $\mathrm{~kg} / \mathrm{m}^{3}$ \\
Elastic modulus & 10 & $\mathrm{MPa}$ \\
Poisson's ratio & 0.3 & - \\
Cohesion & 24.44 & $\mathrm{kPa}$ \\
Friction angle & 29.44 & 0.564 \\
Coefficient of friction & 0.62 & - \\
Moisture content & 18.62 & $\%$ \\
\hline
\end{tabular}

TABLE 3: Laboratory results of the direct shear test.

\begin{tabular}{|c|c|c|c|c|c|c|}
\hline Plant species & Root angle with the horizontal direction & Curve fitting & $R^{2}(\%)$ & $c(\mathrm{kPa})$ & $\tan \varphi$ & $\varphi\left({ }^{\circ}\right)$ \\
\hline & - & $y=0.5646 x+4.435$ & 99.43 & 4.435 & 0.564 & 29.449 \\
\hline No root & $90^{\circ}+90^{\circ}$ & $y=0.6890 x+7.792$ & 99.62 & 7.792 & 0.689 & 34.567 \\
\hline M. multiflora & $\begin{array}{l}45^{\circ}+45^{\circ} \\
45^{\circ}+90^{\circ}\end{array}$ & $\begin{array}{l}y=0.7197 x+7.085 \\
y=07532 x+8.292\end{array}$ & $\begin{array}{l}99.47 \\
9953\end{array}$ & $\begin{array}{l}7.085 \\
8292\end{array}$ & 0.719 & 35.743 \\
\hline
\end{tabular}

horizontal type [37]. The root is an ideal linear elastic material and follows the generalized Hooke's law [38]. In the stability analysis of ecological slope protection, since only root tension is considered (similar to the characteristics of steel cables), truss flexible rod element T2D2 is usually used for simulation. However, in the indoor direct shear test, in addition to the tensile force caused by the displacement between the upper and lower soil bodies, the shear force should also be considered. Therefore, this study used the B31 beam element with a vertical length of $20 \mathrm{~mm}$ or inclined length of $28.28 \mathrm{~mm}$ and a diameter of $0.7 \mathrm{~mm}$ to simulate the plant root system with different angles $\left(90^{\circ}+90^{\circ}, 90^{\circ}+45^{\circ}\right.$, $45^{\circ}+45^{\circ}$ ). The elastic modulus of the root of Magnolia multiflorum is $0.64-2.33 \mathrm{GPa}$, Poisson's ratio is 0.3 , and the density is $1691 \mathrm{~kg} / \mathrm{m}^{3}$. The specific root distribution is shown in Figure 5.

The contact in the simulation of the direct shear test mainly includes the contact of the soil and the contact between the roots and the soil. The "Surface-to-Surface contact" was adopted between the soils, the upper and the down soil contact surfaces are selected as "Master surface" and "Slave surface," respectively. The "Penalty formula" is used to calculate the friction force in the tangential behavior, and the contact type in the normal behavior is "hard" 


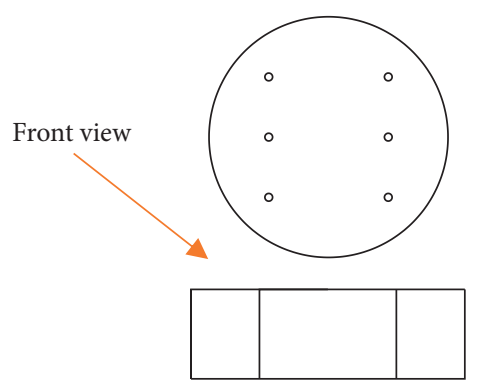

(a)
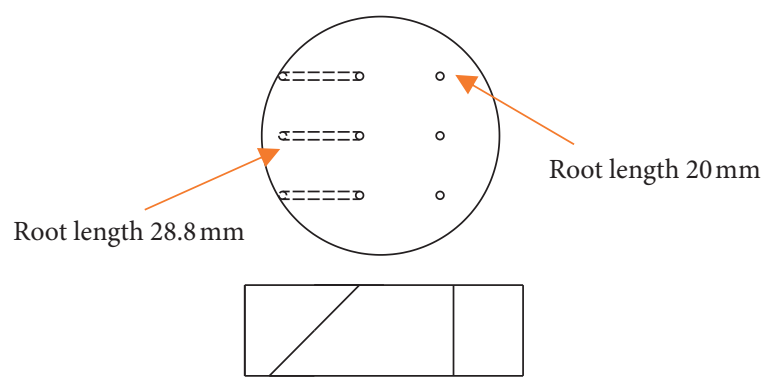

(b)

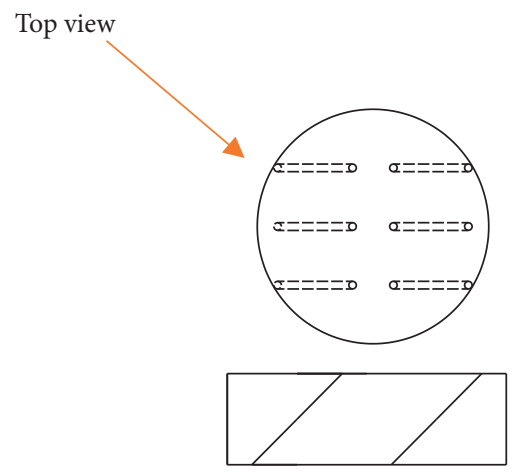

(c)

Figure 5: Top view and main view of three root insertion modes: (a) $90^{\circ}+90^{\circ}$; (b) $90^{\circ}+45^{\circ}$; (c) $45^{\circ}+45^{\circ}$.

contact. The contact between the roots and soil was modeled by the embedded region constraints model in the ABAQUS constraint menu, and the roots were treated as embedded bodies.

The simulation did not take into account the shear rate, which simplified the test process appropriately, because the time of soil failure will not affect the results. Stress boundary conditions were used to simulate the vertical pressure, and displacement boundary conditions were used to play the role of the shear box. The numerical simulation was carried out following three steps: the initial step, load step, and shear step. The first step is to define the properties of the soil-soil and soil-root contact surfaces and fix the displacement of the specimen in the $x$ and $y$ directions and the vertical displacement of the lower soil. In the second step, a vertical load was applied to the top surface of the upper soil. Since the amount of soil in the direct shear test is small, the influence of the soil gravity factors was ignored for simplification. The last step is to release the $x$-direction constraint of the lower soil and apply a horizontal displacement of $10 \mathrm{~mm}$ to simulate the shearing process. Taking the $90^{\circ}$ embedded root system as an example, after the shearing was completed, the root-soil composite model is shown in Figure 6.

Taking the model under $250 \mathrm{kPa}$ vertical load as an example, the equivalent stress cloud diagram of the composite and root in the shear direction is shown in Figure 7. It can be seen that the stress concentration of the soil appeared on the shear surface, and the stress is mainly concentrated in the soil in contact with the root. The peak shear stress of specimens with roots was much greater than that without roots. When the root system was embedded at $90^{\circ}$ and $45^{\circ}$, the peak shear stress of the root system was the largest. After the simulation was finished, the shear stress on the shear plane and the $x$-direction displacement of the lower soil were output, the relationship between the shear stress and shear displacement under normal stress is plotted, and its peak or the stable value was taken as its shear strength.

\section{Results}

3.1. Shear Stress and Shear Displacement Curves. The shear stress and the shear displacement are recorded in Figure 8. The comparison between curves of laboratory test and numerical simulation indicated that the error between results of laboratory test and numerical simulation of the specimen without root was small, and the embedding of the root increased the error; especially when the embedded root system is inclined to the soil, the error is greater. Besides, in the initial stage of the stress-strain curve, two curves were not entirely consistent, and the finite element simulation curve rose relatively faster and reaches the peak intensity soon. The reason for this phenomenon is that in order to simplify the simulation process, the shear rate was not controlled deliberately, which has little influence on the peak value of the curve. Although the shear stress and displacement curves were not completely coincident, the variation trend of each curve was similar, and the predicted shear strength had a good agreement with the laboratory result.

3.2. Relationship between Shear Strength and Vertical Load. According to the results of the direct shear test in the laboratory and numerical simulation, their shear strength 


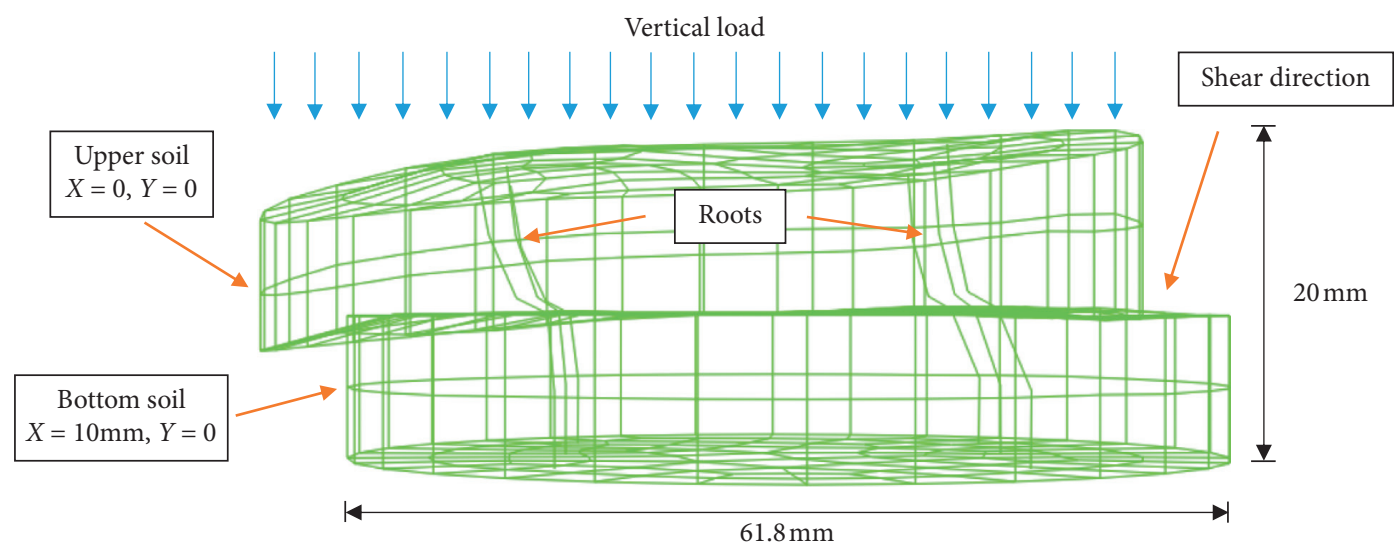

FIgURE 6: Numerical simulation of the laboratory direct shear test.

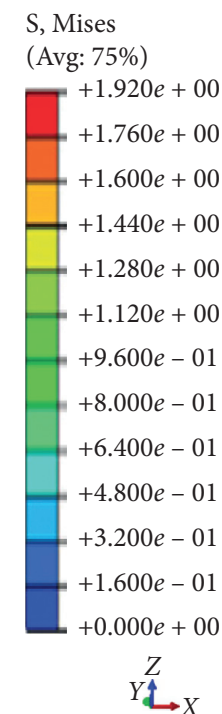

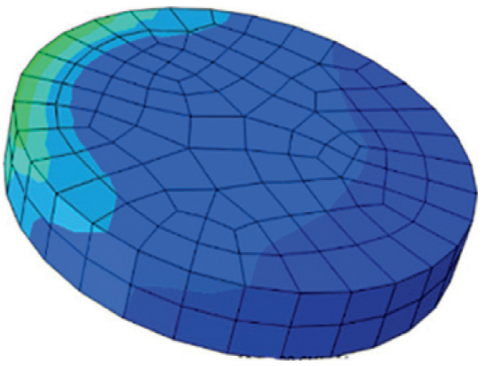

No root

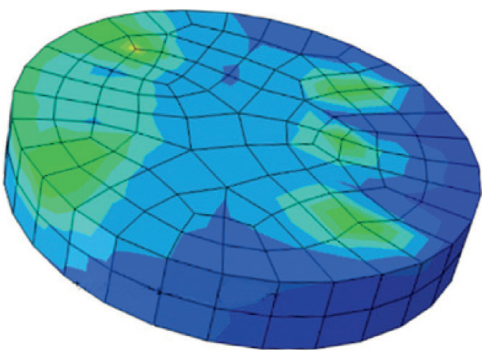

$90^{\circ}+45^{\circ}$

(a)

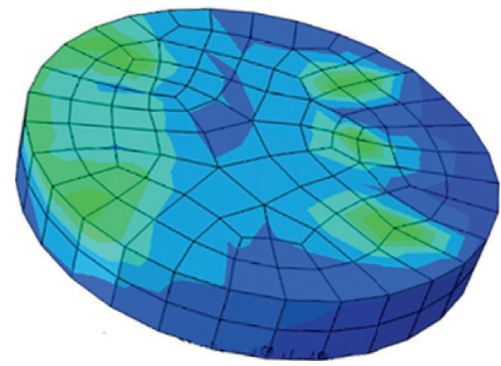

$90^{\circ}+90^{\circ}$

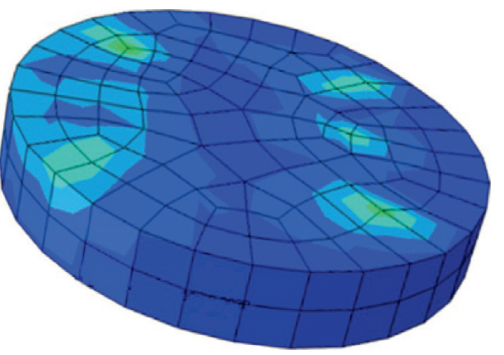

$45^{\circ}+45^{\circ}$

S, Mises

(Avg: 75\%)

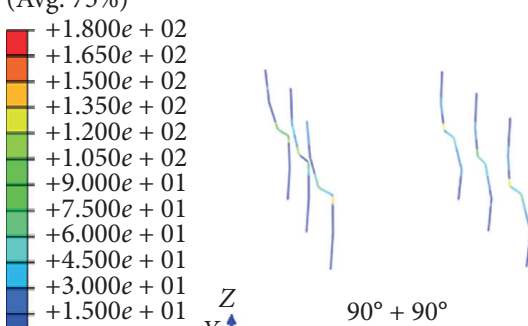

$+1.500 e+01$

$+0.000 e+00 \stackrel{\mathcal{L}}{\longrightarrow} X$

$90^{\circ}+90^{\circ}$

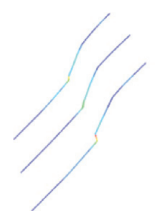

$45^{\circ}+90^{\circ}$
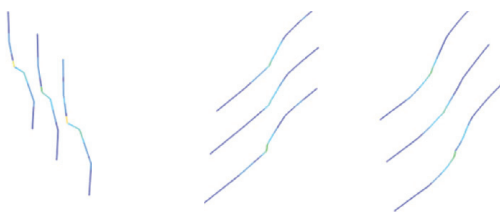

$45^{\circ}+45^{\circ}$

(b)

FIGURE 7: The stress cloud diagram of the composite and plant roots: (a) equivalent stress of bottom soil; (b) equivalent stress of plant roots.

had no significant difference, as shown in Figure 9. For the multiple groups of tests, the simulation results are relatively good, with an average relative error of $2.9 \%$, and a maximum relative error of $5.2 \%$. The simulation curves of the specimen without the root were nearly coincident with the test curve; after adding the root, the error started to increase, especially after plant roots are inserted into the soil at different angles. Under normal circumstances, the simulation process is considered feasible if the differences between simulation results and test results are within $\pm 20 \%$ [39]. There are two 


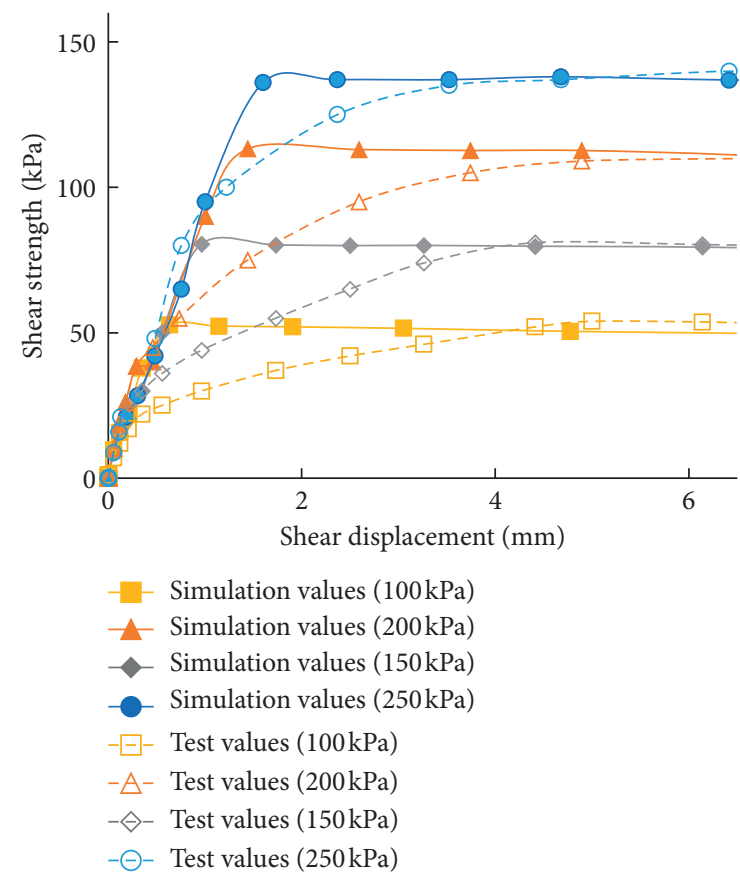

(a)

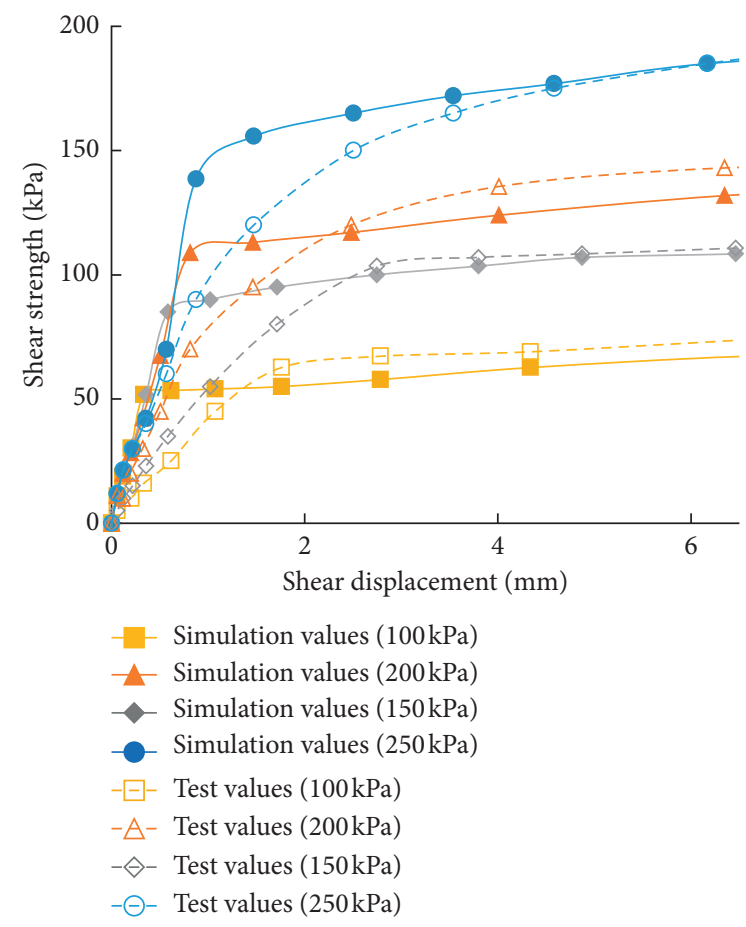

(c)

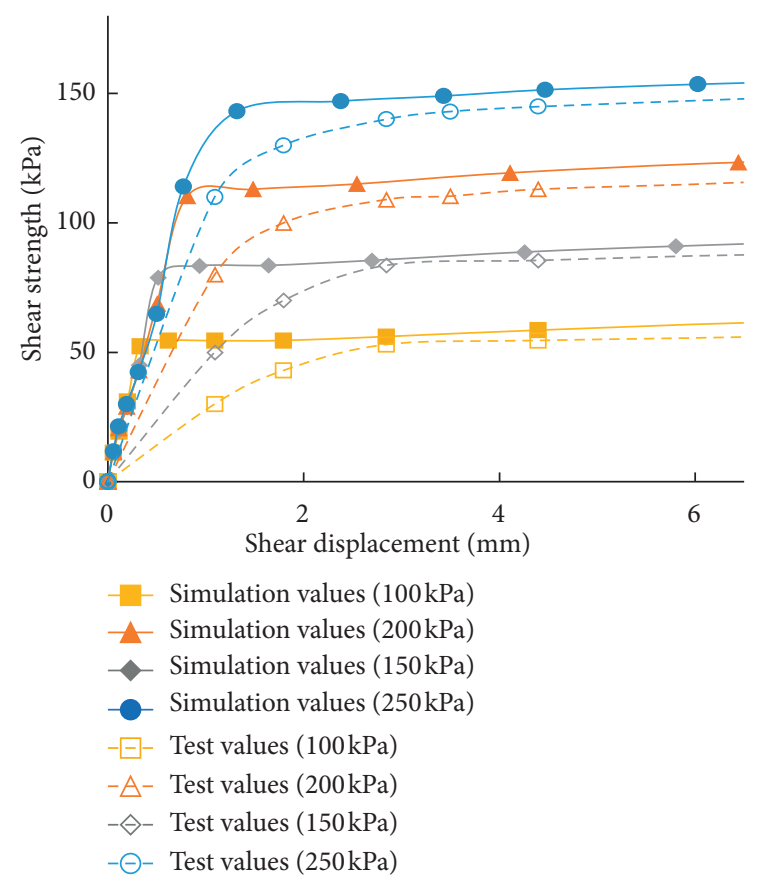

(b)

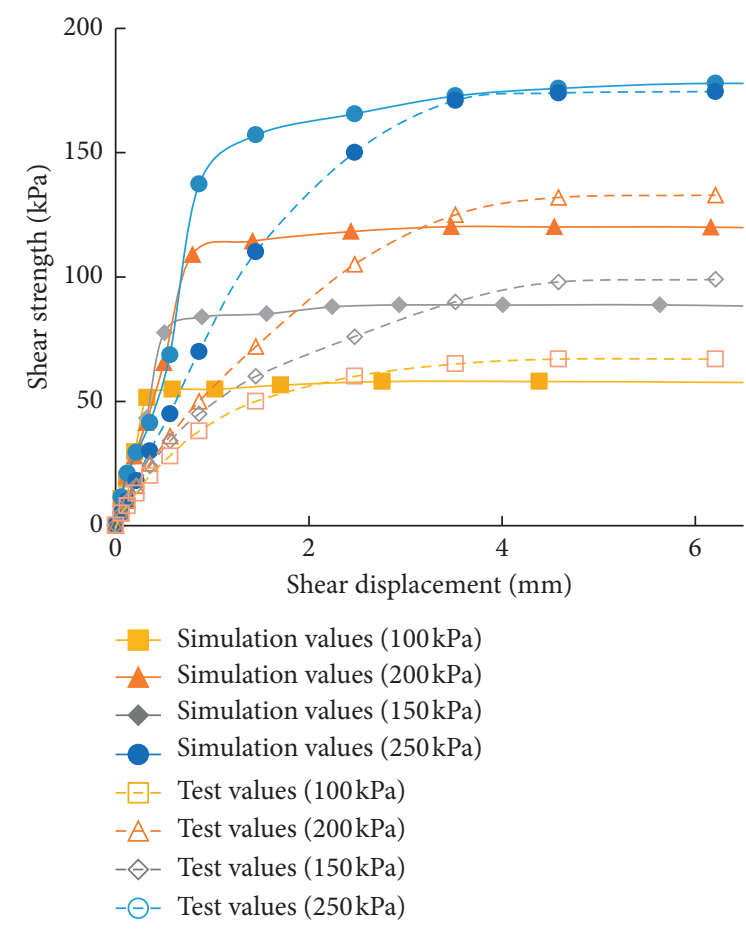

(d)

Figure 8: Shear stress-displacement curves of root-soil composites with different root arrangement: (a) ordinary soil; (b) $90^{\circ}+90^{\circ}$; (c) $90^{\circ}+45^{\circ}$; (d) $45^{\circ}+45^{\circ}$.

main reasons for this error: (1) it is difficult to precisely control the inclination angle of the root inserted into the soil while root embedding in the soil at various angles in the laboratory test, and (2) there are also differences between the B31 beam element and the actual root during the finite element numerical simulation.
3.3. Relationship between Shear Strength and Root Embedding Angle. To make the experimental results more apparent and the data laws more straightforward, the root diameter was appropriately increased, the incremental cohesion force of " $a$ " from $0^{\circ}$ to $90^{\circ}$ was recorded sequentially, and the data records are shown in Table 4. 


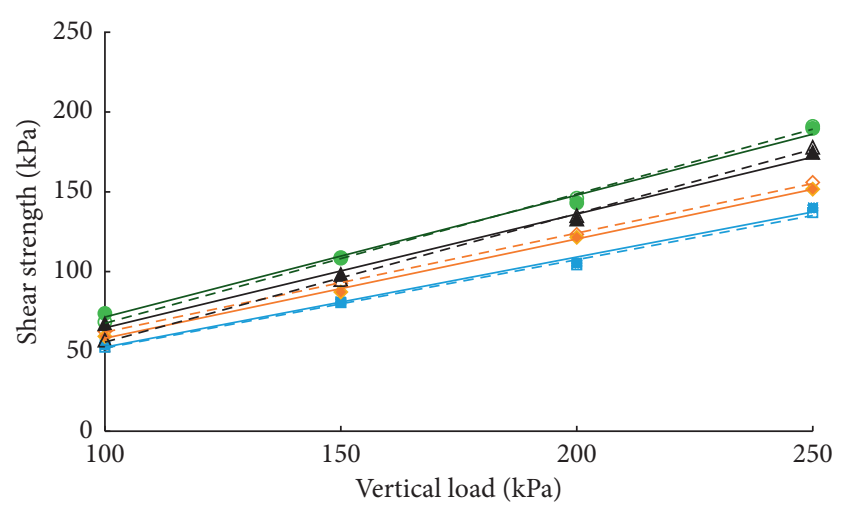

$\square$ Numerical simulation value of ordinary soil

- Test values of common soil

$\diamond$ Numerical simulation value of $90^{\circ}+90^{\circ}$

- Test value of $90^{\circ}+90^{\circ}$

- Numerical simulation value of $90^{\circ}+45^{\circ}$

- Test value of $90^{\circ}+45^{\circ}$

$\Delta$ Numerical simulation value of $45^{\circ}+45^{\circ}$

- Test value of $45^{\circ}+45^{\circ}$

FIGURE 9: Relationship curve between shear strength and vertical load.

TABLE 4: Incremental cohesion values at various angles.

\begin{tabular}{lc}
\hline Angle $\left(^{\circ}\right)$ & Increase in cohesion $(\mathrm{kPa})$ \\
\hline 10 & 7.13 \\
20 & 7.37 \\
30 & 7.51 \\
40 & 7.59 \\
50 & 7.63 \\
60 & 7.65 \\
70 & 7.65 \\
80 & 7.65 \\
90 & 7.64 \\
\hline
\end{tabular}

Finite element simulations were based on theoretical studies to analyze the effect of plant embedding angle on the shear strength of the root-soil composite and were also further combined with theory to verify the accuracy of the model. The roots were embedded in the soil model at different angles, the shear strength of the soil without roots was compared with that of the composite material, the effect of roots on the cohesion increment of the soil was analyzed, and the correlation curve between the root angle and the cohesion increment is plotted in Figure 10.

It can be seen that the simulation results and the theoretical analysis results showed the same pattern. The cohesion increment was the greatest when the root system was embedded at an angle of about $64^{\circ}$. The curve of formula (4) was drawn as the solid line in Figure 10, it can be seen that the curve first rose and then dropped, and the cohesive force reached its peak at $29^{\circ}$. Besides, when the inserted angle of the root was greater than $90^{\circ}$, the shear strength increment was small or even less than the soil without root; combining this with finite element simulation results, it can be seen that when " $\alpha$ " $>90^{\circ}$, the root was compressed and cannot

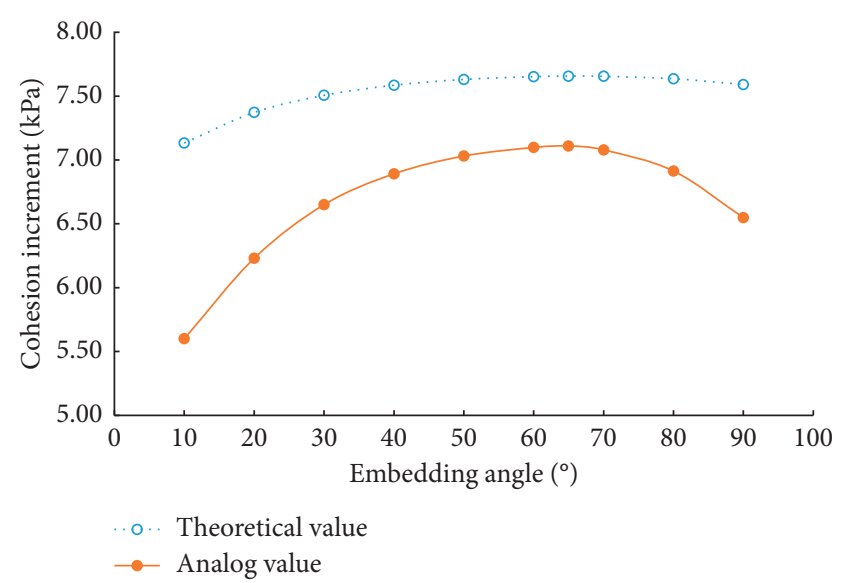

FIGURE 10: Relationship curve between root embedding angle and cohesion incremental.

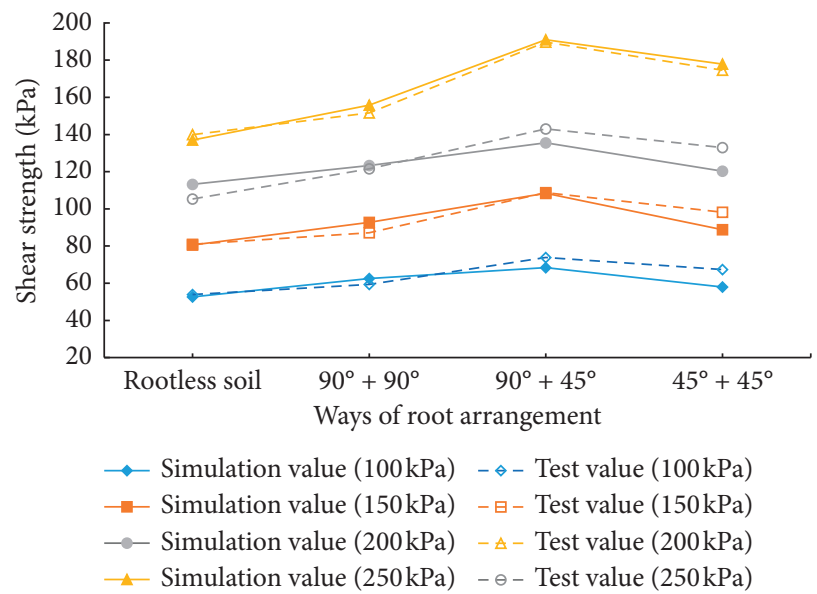

Figure 11: The relation curve between cloth root and shear strength.

withstand the pressure so that the material properties cannot be fully developed, and the reinforcement effect of the root was not pronounced.

3.4. Optimal Arrangement of Roots in the Soil. The above study combines theoretical analysis with finite element simulations to explore the effect of a single embedding angle on cohesion increment. It was determined that the angle of root entry had an effect on the viscous cohesion increment of the composites. In the actual project, the number of roots planted on the slope is relatively large, and there are various combinations between roots and roots; for example, the same single inclination arrangement can be used, or mixed roots can be used, and the development of suitable rooting method to effectively expand the root reinforcement effect on the soil is crucial. The study of single and mixed rooting methods was carried out using both laboratory tests and numerical simulations. Due to the limitation of the size of the straight shear test block, only two better inclination angles of $45^{\circ}$ and $90^{\circ}$ have been used for this combination. The plotting of the rooting method and shear strength 
correlation curve is as follows (Figure 11), where the dashed line is the test result, and the solid line is the simulation result. The analysis of the data shows that when the soil contains multiple roots, different rooting methods will also affect the shear strength of the soil. Three types of rooting methods were used, with the $90^{\circ}+45^{\circ}$ mixed rooting method having significantly better shear resistance than singlerooted soils.

\section{Conclusions}

This study conducted a finite element simulation of the direct shear test of the root-soil composite material. The simulation results were compared with the laboratory results to verify the feasibility of the model. At the same time, some application prospects of the model were proposed here; that is, the effect of root embedding angle on cohesive force increment was analyzed through numerical simulation, and the effect of root arrangement in soil on shear strength was explored. For some cases that are not easy to realize by experimental methods, numerical simulation can show its unique advantages. The following conclusions can be drawn:

(1) The root system of Magnolia multiflorum effectively improved the shear strength of the soil, and its enhancement effect was about $10 \%-40 \%$. In the direct shear test, the shear stress presented a trend of rapid increasing first and then gradually slowing down until it is stable. The maximum or stable value was considered as the shear strength of the material. The tensile force of the plant root system resisted part of the shear force; therefore, the shear resistance of the root-soil composite has been improved. Under the same rooting method, the shear strength increases with the increase of vertical pressure, showing a linear relationship. Combining this with the Coulomb formula, it can be seen that plant roots have little effect on the friction angle of the soil and have a good effect on the cohesion enhancement, which can significantly increase the stability of the slope

(2) The shear strength is not only affected by factors such as the root diameter and root cross-section ratio but is also related to the manner of root distribution and the angle between the root and shear surface. Through theory, experiment, and simulation results, it can be seen that the root was inserted into the soil at different angles, and there is a difference in the improvement of the root-soil composite shear strength. When the inclination angle of the root is around $64^{\circ}$, the shearing strength of the soil was much improved, and when the inclination angle of the root was greater than $90^{\circ}$, the effect of roots on the soil was not pronounced. Besides, in the case of multiple root distributions, the shear strength of the $45^{\circ}+90^{\circ}$ distribution was the largest; that is, the shear strength of the mixed root distribution manner is larger than that of the single root distribution manner
(3) This paper explored the above problems by means of numerical simulation, and the conclusions obtained are consistent with the theoretical analysis and experimental results, the average value of the relative error of shear strength obtained from the multiple sets of tests was $2.9 \%$, and the maximum relative error was $5.2 \%$. After multiple verifications, it is feasible to study the shear strength of the root-soil composite by numerical simulation. The research results and research methods of this article have a good guiding significance for the development of related research on root growth regulation and slope protection

\section{Data Availability}

All data used to support the findings of this study are included within the article.

\section{Conflicts of Interest}

The authors declare no conflicts of interest.

\section{Authors' Contributions}

Conceptualization was done by ZiFan Sui and Wen Yi; methodology was prepared by ZiFan Sui; resources and software were provided by ZiFan Sui; validation was conducted by ZiFan Sui, Wen Yi, and YunGang Lu; formal analysis was done by ZiFan Sui; investigation was performed by ZiFan Sui; data curation was done by Liang Deng; the original draft was written by ZiFan Sui; reviewing and editing were done by ZiFan Sui; visualization, supervision, and project administration were carried out by ZiFan Sui; funding acquisition was contributed by Wen Yi. All authors have read and agreed to the published version of the manuscript.

\section{Acknowledgments}

This research was funded by the Introduction of Key Technologies for Landscape Restoration of Deep Cut Slopes, under grant number 2015-4-38, and Research on Key Technology of Ecological Landscape Restoration of Highway Slope Road in Ecological Fragile Area, under grant number 201803.

\section{References}

[1] L. Yang, M. Yang, and G. Yang, "Modeling fractures and cracks on tree branches," Computers \& Graphics, vol. 80, pp. 63-72, 2019.

[2] Y. Yao, J. Ni, and J. Li, "Stress-dependent water retention of granite residual soil and its implications for ground settlement," Computers and Geotechnics, vol. 129, Article ID 103835, 2021.

[3] G. B. Bischetti, M. Di Fi Dio, and F. Florineth, "On the origin of soil bioengineering," Landscape Research, vol. 39, no. 5, pp. 583-595, 2014. 
[4] Y. P. Dhital, R. B. Kayastha, and J. Shi, "Soil bioengineering application and practices in Nepal," Environmental Management, vol. 51, no. 2, pp. 354-364, 2013.

[5] L. Giupponi, G. Borgonovo, A. Giorgi, and G. B. Bischetti, "How to renew soil bioengineering for slope stabilization: some proposals," Landscape and Ecological Engineering, vol. 15, no. 1, pp. 37-50, 2019.

[6] F. Rey, C. Bifulco, G. B. Bischetti et al., "Soil and water bioengineering: practice and research needs for reconciling natural hazard control and ecological restoration," Science of the Total Environment, vol. 648, pp. 1210-1218, 2019.

[7] H. Zhu, L. M. Zhang, T. Xiao, and X. Y. Li, "Enhancement of slope stability by vegetation considering uncertainties in root distribution," Computers and Geotechnics, vol. 85, pp. 84-89, 2017.

[8] A. Gonzalez-Ollauri and S. B. Mickovski, "Plant-soil reinforcement response under different soil hydrological regimes," Geoderma, vol. 285, pp. 141-150, 2017.

[9] N. Pollen and A. Simon, "Estimating the mechanical effects of riparian vegetation on stream bank stability using a fiber bundle model," Water Resources Research, vol. 41, no. 7, Article ID W07025, 2005

[10] M. Pallewattha, B. Indraratna, A. Heitor, and C. Rujikiakamjorn, "Shear strength of a vegetated soil incorporating both root reinforcement and suction," Transportation Geotechnics, vol. 18, pp. 72-82, 2018.

[11] T. C. Hales and C. F. Miniat, "Soil moisture causes dynamic adjustments to root reinforcement that reduce slope stability," Earth Surface Processes and Landforms, vol. 42, no. 5, pp. 803-813, 2017.

[12] T. Watson, "In situ shear tests of soil blocks with roots," Canadian Geotechnical Journal, vol. 35, no. 4, pp. 579-590, 1998.

[13] T. H. Wu, P. E. Beal, and C. Lan, "In-situ shear test of soil-root systems," Journal of Geotechnical Engineering, vol. 114, no. 12, pp. 1376-1394, 1988.

[14] C.-C. Fan and M.-H. Tsai, "Spatial distribution of plant root forces in root-permeated soils subject to shear," Soil and Tillage Research, vol. 156, pp. 1-15, 2016.

[15] T. H. Wu, W. P. McKinnell III, and D. N. Swanston, "Strength of tree roots and landslides on Prince of Wales island, Alaska," Canadian Geotechnical Journal, vol. 16, no. 1, pp. 19-33, 1979.

[16] T. H. Wu, R. M. Mcomber, R. T. Erb, and P. E. Beal, "Study of soil-root interaction," Journal of Geotechnical Engineering, vol. 114, no. 12, pp. 1351-1375, 1988.

[17] G. B. Bischetti, E. A. Chiaradia, T. Epis et al., "Root cohesion of forest species in the Italian alps," Plant \& Soil, vol. 324, no. 1-2, pp. 71-89, 2009.

[18] M. Zhun, S. A. Laurent, G. Marie et al., "Engineering ecological protection against landslides in diverse mountain forests: cchoosing cohesion models," Ecological Engineering, vol. 45, pp. 55-69, 2012.

[19] P. P. Capilleri, M. Cuomo, E. Motta, and M. Todaro, "Experimental investigation of root tensile strength for slope stabilization," Indian Geotechnical Journal, vol. 49, no. 6, pp. 687-697, 2019.

[20] W. T. Ted, R. Mily, G. Donald et al., "Regulation of root angle and gravitropism," G3: Genes, Genomes, Genetics, vol. 8, no. 12, pp. 3841-3855, 2018.

[21] L. C. Williamson, S. P. Ribrioux, A. H. Fitter, and H. M. O. Leyser, "Phosphate availability regulates root system architecture in arabidopsis," Plant Physiology, vol. 126, no. 2, pp. 875-882, 2001.
[22] T. C. Hales, C. R. Ford, T. Hwang, J. M. Vose, and L. E. Band, "Topographic and ecologic controls on root reinforcement," Journal of Geophysical Research, vol. 114, no. F3, Article ID F03013, 2009.

[23] C. Wang, W. Ng, N. Jun Jun, and K. L. Anthony, "The effects of plant growth and spacing on soil hydrological changes: a field study," Géotechnique, vol. 70, no. 10, pp. 1-41, 2019.

[24] S. Yang, G. Xiaowei, and X. Xiaochuan, "Ecological restoration and mechanical reinforcement effect of slope of tailings reservoir," Environmental Earth Sciences, vol. 80, no. 3, pp. 256-262, 2021.

[25] D. Zhang, J. Cheng, Y. Liu et al., "Spatio-temporal dynamic architecture of living brush mattress: root system and soil shear strength in riverbanks," Forests, vol. 9, no. 8, p. 493, 2018.

[26] G. B. Bischetti, E. A. Chiaradia, V. D’Agostino, and T. Simonato, "Quantifying the effect of brush layering on slope stability," Ecological Engineering, vol. 36, no. 3, pp. 258-264, 2009.

[27] A. Cislaghi, M. Bordoni, C. Meisina, and G. B. Bischetti, "Soil reinforcement provided by the root system of grapevines: quantification and spatial variability," Ecological Engineering, vol. 109, pp. 169-185, 2017.

[28] M. Yang, P. Défossez, F. Danjon, and T. Fourcaud, "Tree stability under wind: simulating uprooting with root breakage using a finite element method," Annals of Botany, vol. 114, no. 4, pp. 695-709, 2014.

[29] D.-G. Lin, B.-S. Huang, and S.-H. Lin, "3-D numerical investigations into the shear strength of the soil-root system of Makino bamboo and its effect on slope stability," Ecological Engineering, vol. 36, no. 8, pp. 992-1006, 2010.

[30] S. B. Mickovski, A. Stokes, R. van Beek, M. Ghestem, and T. Fourcaud, "Simulation of direct shear tests on rooted and non-rooted soil using finite element analysis," Ecological Engineering, vol. 37, no. 10, pp. 1523-1532, 2011.

[31] W. Chungen, H. Kaicheng, Z. Nan et al., "Discussion on ecological protection technology of high and steep slope of expressway," IOP Conference Series: Earth and Environmental Science, vol. 632, no. 2, pp. 220-222, 2021.

[32] M. Li, Y. Yang, S. Wu, and G. Xu, "On ecological slope protection technology of highway construction in Tibet," E3S Web of Conferences, vol. 233, pp. 1151-1155, 2021.

[33] W. Shaowei, C. Degou, L. Song, and Y. Jianping, "Performance test and stability analysis of jute ecological bcag on subgrade slope," E3S tWeb of Conferences, vol. 233, pp. 1133-1137, 2021.

[34] W. Dongdong, Y. Zaijian, C. Yitong et al., "Characterisation of soil erosion and overland flow on vegetation-growing slopes in fragile ecological regions: a review," Journal of Environmental Management, vol. 285, no. 1, pp. 115-120, 2021.

[35] S. Likitlersuang, A. Takahashi, and K. H. Eab, "Modeling of root-reinforced soil slope under rainfall condition," Engineering Journal, vol. 21, no. 3, 2017.

[36] T. S. Nguyen, "Stability analysis of vegetated residual soil slope under rainfall conditions," Environmental Geotechnics, vol. 7, no. 5, pp. 1-45, 2018.

[37] K. H. Eab, A. Takahashi, and S. Likitlersuang, "Centrifuge modelling of root-reinforced soil slope subjected to rainfall infiltration," Géotechnique Letters, vol. 4, no. 3, pp. 211-216, 2014.

[38] K. H. Eab, S. Likitlersuang, and A. Takahashi, "Laboratory and modelling investigation of root-reinforced system for slope 
stabilisation," Soils and Foundations, vol. 55, no. 5, pp. 1270-1281, 2015.

[39] U. Leknoi and S. Likitlersuang, "Good practice and lesson learned in promoting vetiver as solution for slope stabilisation and erosion control in Thailand," Land Use Policy, vol. 99, 2020 . 